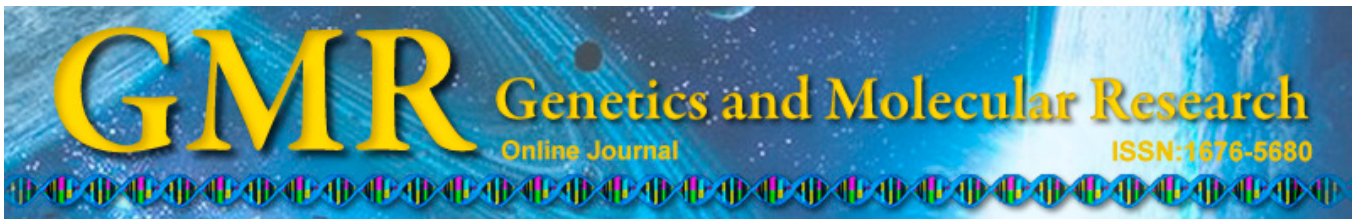

$\underline{\text { Short Communication }}$

\title{
Genome-wide association with residual body weight gain in Bos indicus cattle
}

\author{
M.H.A. Santana ${ }^{1}$, R.C. Gomes ${ }^{2}$, Y.T. Utsunomiya ${ }^{3}$, H.H.R. Neves ${ }^{3,4}$, \\ F.J. Novais ${ }^{1}$, M.N. Bonin ${ }^{2}$, H. Fukumasu ${ }^{1}$, J.F. Garcia ${ }^{3,5}$, P.A. Alexandre ${ }^{1}$, \\ G.A. Oliveira Junior ${ }^{1}$, L.L. Coutinho ${ }^{6}$ and J.B.S. Ferraz ${ }^{1}$ \\ ${ }^{1}$ Faculdade de Zootecnia e Engenharia de Alimentos, Pirassununga, SP, Brasil \\ ${ }^{2}$ Empresa Brasileira de Pesquisa Agropecuária, Campo Grande, MS, Brasil \\ ${ }^{3}$ Faculdade de Ciências Agrárias e Veterinárias, \\ Universidade Estadual Paulista, Jaboticabal, SP, Brasil \\ ${ }^{4}$ GenSys Consultores Associados S/C Ltda, Porto Alegre, RS, Brasil \\ ${ }^{5}$ Faculdade de Medicina Veterinária de Araçatuba, Universidade Estadual Paulista, \\ Araçatuba, SP, Brasil \\ ${ }^{6}$ Escola Superior de Agricultura Luiz de Queiroz, Universidade de São Paulo, \\ Piracicaba, SP, Brasil \\ Corresponding author: M.H.A. Santana \\ E-mail: miguel-has@hotmail.com
}

Genet. Mol. Res. 14 (2): 5229-5233 (2015)

Received August 11, 2014

Accepted December 2, 2014

Published May 18, 2015

DOI http://dx.doi.org/10.4238/2015.May.18.14

ABSTRACT. Weight gain is a key performance trait for beef cattle; however, attention should be given to the production costs for better profitability. Therefore, a feed efficiency trait based on performance can be an interesting approach to improve performance without increasing food costs. To identify candidate genes and genomic regions associated with residual body weight gain (RWG), we conducted a genome-wide association study (GWAS) with 720 Nellore cattle using the GRAMMAR-Gamma association test. We identified 30 significant single nucleotide polymorphisms (SNPs), 
especially on chromosomes $2,8,12$, and 17 . Several genes and quantitative train loci (QTLs) present in the regions identified were appointed; we highlight DMRT2 (doublesex and mab-3 related transcription factor 2), IFFO2 (intermediate filament family orphan 2), LNX2 (ligand of numb-protein X 2), MTIF3 (mitochondrial translational initiation factor 3), and TRNAG-CCC (transfer RNA glycine anticodon CCC). The metabolic pathways that can explain part of the phenotypic variation in RWG are related to oxidative stress and muscle control.

Key words: Beef cattle; Nellore; Feed efficiency; Average daily gain; Genome-wide association study; Single nucleotide polymorphism

\section{INTRODUCTION}

Feed efficiency traits are proposed to reduce costs of beef cattle. Generally feed efficiency traits, such as residual feed intake, focus on feed intake and not on weight gain. The feed efficiency traits correlated with performance, such as the feed conversion ratio, have antagonistic responses to feed intake (Arthur et al., 2001). In this context, the residual body weight gain (RWG) was proposed as a feed efficiency trait that could increase growth rates without changing feed intake (Berry and Crowley, 2012). However few studies have been performed with this trait. A possible strategy to identify candidate genes related to underexplored phenotypes is through the use of genomic information, mainly by genome-wide association studies (GWAS) that relate hundreds of thousands of single nucleotide polymorphisms (SNPs) with a phenotype (Goddard and Hayes, 2009). The objective of this study was to identify the SNPs associated with RWG and explore genomic regions surrounding the significant markers searching for candidate genes that may be linked to RWG.

\section{MATERIAL AND METHODS}

The data used in this study are a compilation of 11 different experiments, which were approved by their respective ethic committees (Gomes et al., 2013; Santana et al., 2013). Phenotypic and genotypic information from 720 steers and young Nellore bulls were used in this study. The collection of phenotypes in the feedlot lasted for no less than 70 days and was performed in individual pens and collective stalls (GrowSafe and Calan gates). Individual daily feed intake was measured and adjusted to dry matter intake (DMI), and each animal was weighed periodically to obtain the metabolic body weight (MBW). The average daily gain (ADG) was estimated as the slope of the linear regression of weights by experimental days. The RWG was estimated as the regression equation residue of ADG on MBW, DMI, contemporary group (experimental group), and gender (young bull or steer). There was no evidence that the data deviated from normality (Shapiro-Wilk test) and RWG had an average of 0:00 0:31.

Genomic information of about 350,000 SNPs in autosomal chromosomes (Chr) was used for association tests after quality control. More details of genomic data are described by Santana et al. (2014). The GRAMMAR-Gamma (Svishcheva et al., 2012) association test was used and the analysis was performed in R using the GenABEL package (Aulchenko et al., 
2007). A modified Bonferroni correction of $5 \%$ for multiple testing $\left(\alpha=9.27 \times 10^{-5}\right)$ was used as the threshold (Gao et al., 2008). The 10 most significant SNPs have been described and the flanking candidate genes investigated (Kinsella et al., 2011).

\section{RESULTS AND DISCUSSION}

Thirty SNPs exceeded the threshold used (Figure 1) in GWAS for RWG of Nellore cattle. The most significant marker was rs $110851489\left(\mathrm{Chr} 12: 32673654, \mathrm{P}=3.97 \times 10^{-6}\right)$ with an estimated allele substitution effect of $0.198 \mathrm{~kg}$ /day. In addition, the QTLs \#20947 and \#20948 (Hu et al., 2013) were previously identified for ADG overlapping this region in Chr12 (Rolf et al., 2012).

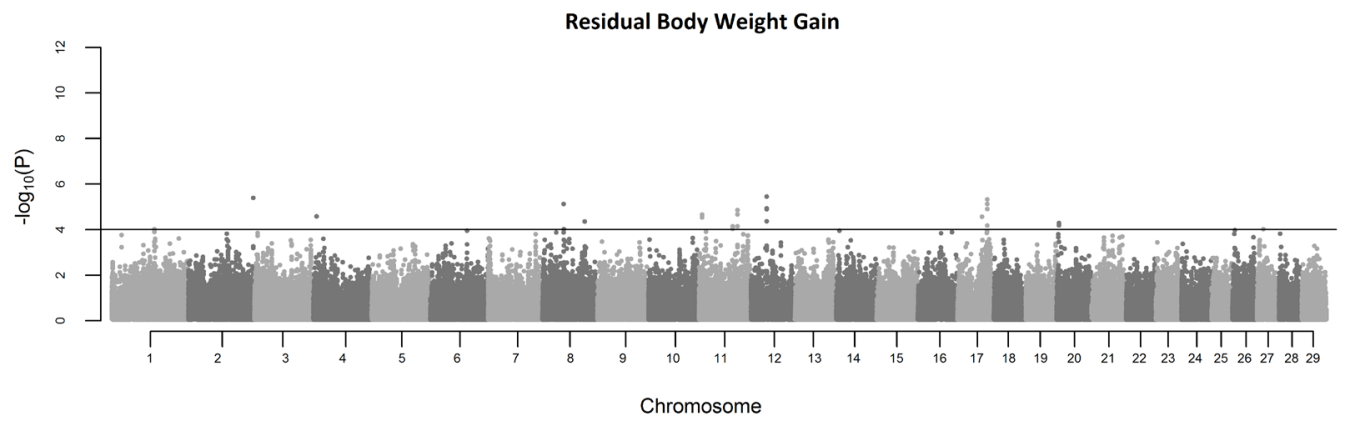

Figure 1. Manhattan plots for residual body weight gain of Nellore bulls and steers. The horizontal lines represent the modified Bonferroni threshold $\left(\alpha=9.27 \times 10^{-5}\right)$.

The genome-wide analysis identified some genomic regions affecting RWG, especially in chromosomes $2,8,12$, and 17 (Table 1). We highlighted five candidate genes in these regions: DMRT2, IFFO2, LNX2, MTIF3, and TRNAG-CCC.

Table 1. Summary of the 10 most significant SNPs for residual body weight gain.

\begin{tabular}{|c|c|c|c|c|c|c|c|}
\hline SNP ID & $\mathrm{Chr}^{1}$ & Position $(b p)^{2}$ & $\mathrm{SNP}^{3}$ & Beta $^{4}$ & $P$ value & Candidate Gene & Distance $(\mathrm{kb})^{2}$ \\
\hline rs110851489 & 12 & 32673654 & $\mathrm{~A} / \mathrm{G}$ & 0.198 & $3.97 \times 10^{-6}$ & $L N X 2$ & 25.9 \\
\hline rs134566411 & 2 & 134259580 & $\mathrm{C} / \mathrm{T}$ & 0.164 & $4.52 \times 10^{-6}$ & $I F F O 2$ & 32.8 \\
\hline rs110882929 & 17 & 61849434 & $\mathrm{~A} / \mathrm{G}$ & 0.077 & $5.30 \times 10^{-6}$ & TRNAG-CCC & 10.4 \\
\hline rs109247561 & 17 & 61850177 & $\mathrm{~A} / \mathrm{C}$ & 0.075 & $8.27 \times 10^{-6}$ & TRNAG-CCC & 9.6 \\
\hline rs109731399 & 8 & 43763099 & $\mathrm{~A} / \mathrm{G}$ & 0.122 & $8.41 \times 10^{-6}$ & $D M R T 2$ & 17.8 \\
\hline rs109186932 & 12 & 32677116 & $\mathrm{C} / \mathrm{T}$ & 0.184 & $1.29 \times 10^{-5}$ & $L N X 2$ & 29.4 \\
\hline rs41624033 & 12 & 32687103 & $\mathrm{~A} / \mathrm{G}$ & 0.184 & $1.29 \times 10^{-5}$ & $M T I F 3$ & 23.5 \\
\hline rs109159874 & 17 & 61853619 & $\mathrm{C} / \mathrm{T}$ & 0.110 & $1.40 \times 10^{-5}$ & $T R N A G-C C C$ & 6.2 \\
\hline rs41847922 & 17 & 61862755 & $\mathrm{C} / \mathrm{T}$ & 0.110 & $1.40 \times 10^{-5}$ & $T R N A G-C C C$ & 2.8 \\
\hline rs109535423 & 12 & 32672924 & $\mathrm{~A} / \mathrm{G}$ & 0.199 & $1.45 \times 10^{-5}$ & $L N X 2$ & 25.2 \\
\hline
\end{tabular}

${ }^{1}$ Autosomal chromosome; ${ }^{2}$ Assembly Bos taurus UMD v3.1; ${ }^{3}$ Illumina TOP strand; ${ }^{4}$ Estimated allele substitution effect.

The possible relationship of these genes to the performance of Bos indicus is still unknown. However the DMRT2 (doublesex and mab-3 related transcription factor 2) gene seems to be associated with sexual dimorphism in embryogenesis and sexual development (Bratuś and Słota, 2009). MTIF3 (mitochondrial translational initiation factor 3), which is close to the 
significant SNP rs41624033 in Chr12, has been associated with control of body mass and obesity in mammals in some studies (McCaffery et al., 2012; Casas-Agustench et al., 2014). This gene is responsible for encoding a nuclear protein that is necessary for the initiation complex formation on mitochondrial ribosomes and differences in its expression can cause oxidative stress (Anvret et al., 2010). The relationship between oxidative stress and weight loss has been reported in humans (Ozata et al., 2002; Keaney et al., 2003) and in livestock (Lykkesfeldt and Svendsen, 2007). This linkage can explain part of the phenotypic difference of RWG, since this complex metabolic pathway is involved in oxidative stress and the control of muscle mass may be closely related to the performance of the animals.

The indicated candidate genes regulate a small part of the complex polygenic control of performance related phenotypes. This study provides supplementary insights into the metabolic pathways related to this kind of trait. Therefore, further studies are necessary to better understand the metabolic pathways for important understudied phenotypes such as the RWG.

\section{ACKNOWLEDGMENTS}

Research supported in part by Fundação de Amparo à Pesquisa do Estado de São Paulo (FAPESP, \#2012/02039-9 and \#2013/20571-2). The contributions of Núcleo de Criadores

de Nelore do Norte do Paraná, Luciano Borges (Rancho da Matinha) and Eduardo Penteado Cardoso (Faz. Mundo Novo) are gratefully acknowledged.

\section{REFERENCES}

Anvret A, Ran C, Westerlund M, Thelander AC, et al. (2010). Possible involvement of a mitochondrial translation initiation factor 3 variant causing decreased mRNA levels in Parkinson's disease. Parkinsons. Dis. 2010: 491751.

Arthur PF, Archer JA, Johnston DJ, Herd RM, et al. (2001). Genetic and phenotypic variance and covariance components for feed intake, feed efficiency, and other postweaning traits in Angus cattle. J. Anim. Sci. 79: 2805-2811.

Aulchenko YS, Ripke S, Isaacs A and van Duijn CM (2007). GenABEL: an R library for genome-wide association analysis. Bioinformatics 23: 1294-1296.

Berry DP and Crowley JJ (2012). Residual intake and body weight gain: a new measure of efficiency in growing cattle. J. Anim. Sci. 90: 109-115.

Bratuś A and Słota E (2009). Comparative cytogenetic and molecular studies of DM domain genes in pig and cattle. Cytogenet. Genome Res. 126: 180-185.

Casas-Agustench P, Arnett DK, Smith CE, Lai CQ, et al. (2014). Saturated fat intake modulates the association between an obesity genetic risk score and body mass index in two US populations. J. Acad. Nutr. Diet. 114: 1954-1966.

Gao X, Starmer J and Martin ER (2008). A multiple testing correction method for genetic association studies using correlated single nucleotide polymorphisms. Genet. Epidemiol. 32: 361-369.

Goddard ME and Hayes BJ (2009). Mapping genes for complex traits in domestic animals and their use in breeding programmes. Nat. Rev. Genet. 10: 381-391.

Gomes RC, Silva SL, Carvalho ME, Rezende FM, et al. (2013). Protein synthesis and degradation gene SNPs related to feed intake, feed efficiency, growth, and ultrasound carcass traits in Nellore cattle. Genet. Mol. Res. 12: 2923-2936.

Hu ZL, Park CA, Wu XL and Reecy JM (2013). Animal QTLdb: an improved database tool for livestock animal QTL/ association data dissemination in the post-genome era. Nucleic Acids Res. 41: 871-879.

Keaney JF, Larson MG, Vasan RS, Wilson PWF, et al. (2003). Obesity and systemic oxidative stress: clinical correlates of oxidative stress in the Framingham Study. Arterioscler. Thromb. Vasc. Biol. 23: 434-439.

Kinsella RJ, Kähäri A, Haider S, Zamora J, et al. (2011). Ensembl BioMarts: a hub for data retrieval across taxonomic space. Database (Oxford). 2011: bar030.

Lykkesfeldt J and Svendsen O (2007). Oxidants and antioxidants in disease: oxidative stress in farm animals. Vet. J. 173: 502-511.

McCaffery JM, Papandonatos GD, Peter I, Huggins GS, et al. (2012). Obesity susceptibility loci and dietary intake in the Look AHEAD Trial. Am. J. Clin. Nutr. 95: 1477-1486. 
Ozata M, Mergen M, Oktenli C, Aydin A, et al. (2002). Increased oxidative stress and hypozincemia in male obesity. Clin. Biochem. 35: 627-631.

Rolf MM, Taylor JF, Schnabel RD, McKay SD, et al. (2012). Genome-wide association analysis for feed efficiency in Angus cattle. Anim. Genet. 43: 367-374.

Santana MHA, Rossi Junior P, Almeida R and Schuntzemberger AMS (2013). Blood cell and metabolic profile of Nellore bulls and their correlations with residual feed intake and feed conversion ratio. Rev. Bras. Saúde E Produção Anim. 14: 527-537.

Santana MHA, Utsunomiya YT, Neves HHR, Gomes RC, et al. (2014). Genome-wide association study for feedlot average daily gain in Nellore cattle (Bos indicus). J. Anim. Breed. Genet. 131: 210-216.

Svishcheva GR, Axenovich TI, Belonogova NM, van Duijn CM, et al. (2012). Rapid variance components-based method for whole-genome association analysis. Nat. Genet. 44: 1166-1170. 